\title{
Safety, efficacy and patient acceptability of drospirenone and estradiol in the treatment of menopausal vasomotor symptoms: a review
}

\author{
Sebastián Carranza-Lira \\ Reproductive Medicine, UMAE \\ Hospital de Ginecología y Obstetricia \\ "Luis Castelazo Ayala" Instituto \\ Mexicano del Seguro Social, México
}

\begin{abstract}
During menopause vasomotor symptoms are one of the main complaints about which women seek medical advice. For symptom control, several therapies have been used, among which hormone therapy has produced good results. One of these is estrogen monotherapy, which unfortunately may induce endometrial hyperplasia in women with an intact uterus. A progestin must be added to avoid this risk. Progestins may induce several secondary effects such as breast tenderness, hirsutism, edema and unfavorable lipid profile modifications. Recently a new progestin called drospirenone has been synthesized and used in combination with estradiol for the treatment of postmenopausal women. This progestin is derived from spironolactone, and lacks estrogenic, androgenic and glucocorticoid activities. Several studies have evaluated safety, efficacy and patient tolerability, and have shown a good profile in all these parameters. All studies agree that the combination of estradiol $1 \mathrm{mg}$ plus drospirenone $2 \mathrm{mg}$ is a good choice for postmenopausal women with vasomotor symptoms.
\end{abstract}

Keywords: estradiol, drospirenone, postmenopause, review

\section{Introduction}

Vasomotor symptoms are one of the main complaints in menopausal women, approximately $85 \%$ of whom experience hot flushes, sweating, throbbing and chilling. ${ }^{1}$

Several treatments have been used to control these symptoms, but the most efficient has proved to be hormone therapy (HT). ${ }^{2}$ This therapy also prevents genitourinary atrophy $^{3}$ and osteoporosis development. ${ }^{4}$

Cardiovascular protection is a controversial theme with HT and current evidence indicates that early prescription, in the first five postmenopausal years, may induce cardiovascular protection. ${ }^{5}$

Estrogen therapy is the best choice for vasomotor symptoms control, but in women with an intact uterus, a progestin must be added to avoid the risk of endometrial hyperplasia or cancer. ${ }^{6}$ Estrogen plus progestin therapies have shown different results for lipid modification, since these androgenic progestins have a deleterious effect on high density lipoprotein cholesterol; ${ }^{7}$ also some progestins are associated with fluid retention which can be associated with edema and breast tenderness and which may impair HT compliance. ${ }^{8}$

A new progestin, drospirenone $(6 \beta, 17 \beta, 15 \beta, 16 \beta$-dimethylen-3-oxo $1 \alpha$-pregn-4ene-21, 17-carbo lactone), has a pharmacological profile very similar to that of endogenous progesterone. ${ }^{9}$ It is derived not from testosterone but from $17 \alpha$-spironolactone. It has progestational activity and lacks androgenic, estrogenic or glucocorticoid activities. Progestational activity is 4 times greater than that of progesterone. ${ }^{10,11}$

The renin-angiotensin-aldosterone system, by aldosterone action, prevents excessive sodium loss, and promotes water retention with concomitant potassium and magnesium loss. ${ }^{9}$

\footnotetext{
Correspondence: Sebastián Carranza-Lira Puente de piedra I50-422 Torre I. Col. Toriello Guerra CP 14050 México DF $\mathrm{Tel} / \mathrm{Fax}+\mathrm{I} 525555284657$

Email scarranzal@mexis.com
} 
In a rat model, drospirenone was shown to have 8 times the antialdosterone potency of spironolactone, and the antagonism exhibited by drospirenone is a result of its affinity for the mineralocorticoid receptor. ${ }^{12}$ Sodium excretion increased from 79.6 to $98.6 \mathrm{mmol} /$ day after drospirenone administration compared with placebo, in which no changes were observed. ${ }^{13}$ Because estrogen stimulates angiotensinogen synthesis, ${ }^{14}$ which promotes sodium and water retention, it can increase blood pressure, but progesterone prevents the interaction of aldosterone with mineralocorticoid receptors, which prevents this effect. Because drospirenone mimics the progesterone effect by the same mechanism it may be useful for hormone therapy.

\section{Safety}

Several studies have considered the safety of drospirenone use in addition to estradiol in postmenopausal women. One of the main goals of these studies has been endometrial safety as assessed by endometrial histology.

In one of these studies in which 1147 women were enrolled and randomized to receive either $1 \mathrm{mg}$ estradiol alone or $1 \mathrm{mg}$ estradiol in addition to $0.5,1,2$ or $3 \mathrm{mg}$ drospirenone, endometrial hyperplasia was found in $4.6 \%$ in the unopposed estradiol group, compared with $0.7 \%$ in patients receiving estradiol plus $2 \mathrm{mg}$ drospirenone. No hyperplasia was reported in the groups receiving $0.5,1$ and $3 \mathrm{mg}$ drospirenone. ${ }^{15}$ Also endometrial thickness did not increase in the estradiol plus drospirenone group, while it was considerably increased by cycle 7 in the group receiving estradiol monotherapy. ${ }^{15}$

In another multicenter, double-blind, randomized, placebo-controlled study in which 225 healthy postmenopausal women aged 45 to 65 years received $1 \mathrm{mg}$ estradiol or 1, 2 or $3 \mathrm{mg}$ drospirenone, it was found that endometrial thickness $\geq 5 \mathrm{~mm}$ was similar between baseline and final examination. Three patients in each of the $1 \mathrm{mg}$ and $2 \mathrm{mg}$ groups and the placebo group had an endometrial thickness $\geq 5 \mathrm{~mm}, 7$ had no hyperplasia and 2 were not biopsied ( 1 in placebo and 1 in $1 \mathrm{mg}$ group). ${ }^{16}$

In another study in which 1142 women between 42 and 75 years age were randomized to receive drospirenone 0.5 , 1, 2 or $3 \mathrm{mg}$ plus estradiol $1 \mathrm{mg}$ or only $1 \mathrm{mg}$ estradiol. The primary outcome variable was endometrial hyperplasia. A proliferative endometrium was found in $50.8 \%$ of those receiving estradiol monotherapy, while in those receiving drospirenone at doses of $0.5,1,2$ or $3 \mathrm{mg}$ it was found in $16.2 \%, 13.0 \%, 8.2 \%$ and $6.2 \%$ respectively. Hyperplasia was diagnosed in $4 \%$ of those with estradiol monotherapy and $0.5 \%$ in the group receiving drospirenone $2 \mathrm{mg}$, with an 0.007 probability of developing hyperplasia. ${ }^{17}$

In another study, in which 90 postmenopausal Korean women were randomized to receive estradiol $1 \mathrm{mg}$ plus drospirenone $2 \mathrm{mg}$ or placebo, a normal endometrium was found in the biopsies of 5 women with endometrial thickness $\geq 5 \mathrm{~mm}, 3$ in the placebo and 2 in the estradiol plus drospirenone group. ${ }^{18}$

Cervical polyps were reported to occur with estradiol and drospirenone therapy, 2 in the 1 or $2 \mathrm{mg}$ drospirenone group and 3 in the $3 \mathrm{mg}$ drospirenone group. ${ }^{16}$ Also endometrial polyps were diagnosed in $3.1 \%$ receiving estradiol and drospirenone therapy compared with $3.0 \%$ receiving estradiol monotherapy. ${ }^{17}$

Lipid levels, blood pressure and coagulation factors have also been evaluated.

\section{Lipids}

When estradiol $1 \mathrm{mg}$ alone or in combination with $0.5,1,2$ or $3 \mathrm{mg}$ drospirenone was evaluated, cholesterol, triglycerides and low density lipoprotein levels were reduced with estradiol plus 0.5 or $2 \mathrm{mg}$ drospirenone, but these changes were less marked with high density lipoprotein and lipoprotein (a). ${ }^{15}$ In another study, mean total cholesterol values decreased in all estradiol plus drospirenone groups but not in the estradiol monotherapy group; also in this latter group triglyceride level increased. HDL-C increased more with drospirenone plus estradiol than with estradiol monotherapy. LDL-C decreased in all treatment groups. Significant increases were found in HDL-C, HDL-C 3, apolipoprotein A1 and total phospholipids with estradiol monotherapy. Estradiol and drospirenone significantly reduced total cholesterol and LDL-C, with a trend toward a decrease in triglycerides and total phospholipids and non-significant increases in apolipoprotein A1, except for the $2 \mathrm{mg}$ group and the estradiol monotherapy group. Larger decreases in apolipoprotein B were seen in estradiol drospirenone groups than in estradiol monotherapy groups. ${ }^{17}$

\section{Blood pressure}

In a multicenter study in which 225 healthy postmenopausal women aged 45 to 65 years received 1, 2 or $3 \mathrm{mg}$ drospirenone plus estradiol, a slight decrease in blood pressure was shown between the treatment groups which was slightly larger than in the placebo group. ${ }^{16}$

In another study in which estradiol $1 \mathrm{mg}$ plus drospirenone $0.5,1,2$ or $3 \mathrm{mg}$ were evaluated, blood pressure decreased in all treatment groups in a subgroup of hypertensive women, 
but no differences were found in those with normal blood pressure. The decrease was greater with drospirenone than with estradiol monotherapy. The greatest decrease was observed in the $3 \mathrm{mg}$ drospirenone group, and diastolic blood pressure significantly decreased in the 0.5 and $2 \mathrm{mg}$ groups. ${ }^{17}$ In another study, $3 \mathrm{mg}$ drospirenone dose also reduced blood pressure without changing potassium levels. ${ }^{19}$ Also, in a small study blood pressure tended to decrease in the estradiol $1 \mathrm{mg}$ plus drospirenone $2 \mathrm{mg}$ group. ${ }^{18}$ Most of the studies agree that $2 \mathrm{mg}$ drospirenone is the minimum effective dose that can achieve a blood pressure decrease..$^{20,21}$

\section{Coagulation}

In a large study in which drospirenone $0.5,1,2$ or $3 \mathrm{mg}$ plus estradiol $1 \mathrm{mg}$ or $1 \mathrm{mg}$ estradiol alone were evaluated, fibrinogen levels decreased in the estradiol monotherapy group but not in the estradiol drospirenone group. Only the $3 \mathrm{mg}$ drospirenone group showed a decrease in plasminogen activator inhibitor antigen and no changes in potassium levels were found. ${ }^{17}$

In a study with 225 women, laboratory examinations found no changes between baseline and 16th week of treatment in any of the estradiol and drospirenone groups. ${ }^{16}$

\section{Efficacy}

Control of hot flushes is one of the most important parameters for assessing HT efficacy, because they are one of the main reasons for women seeking medical advice.

When evaluating $1 \mathrm{mg}$ estradiol alone or $1 \mathrm{mg}$ estradiol plus $0.5,1,2$ or $3 \mathrm{mg}$ drospirenone, frequency and severity of hot flushes was reduced by week 2 in all treatment groups, with no differences between any of drospirenone doses. ${ }^{15}$

In another study in which $1 \mathrm{mg}$ estradiol and 1,2 or $3 \mathrm{mg}$ drospirenone were evaluated, the number of hot flushes decreased in all subjects by the 5 th week of the study. A greater decrease was observed during treatment weeks 3 to 16 in active treatment groups than in the placebo group. The decrease between baseline and 16th week was greater in moderate and severe hot flushes than in mild ones (21.8-29.8 vs $1.0-2.0,7.4-9.6$ vs $1.4-3.7$, respectively). ${ }^{16}$ Another study reported that hot flushes began to decrease at week 2 , with no differences between the groups. ${ }^{17}$

In a small study hot flushes decreased by $48.1 \%$ in the placebo group and by $84.4 \%$ in the estradiol $1 \mathrm{mg}$ plus drospirenone $2 \mathrm{mg}$ group. The decrease in the number of moderate and severe hot flushes was greater in the HT group as early as the first month. Also the number of hot flushes decreased from an average of 27.8 to 31.5 at baseline to 5.8 to 8.6 .
The incidence of sweating episodes decreased $80 \%$ in the hormone group compared with $24 \%$ in the placebo. The incidence of insomnia decreased by $49 \%$ compared with $14 \%$ in the placebo, and depression decreased from $31.4 \%$ to $14.3 \%$, nervousness from $42.9 \%$ to $17.1 \%$ and vaginal dryness from $42.9 \%$ to $2.9 \%$, respectively. ${ }^{18}$

\section{Acceptability}

The evaluation of spotting, breast pain and weight gain are important parameters for evaluating HT, since they will affect women's long term continuation of treatment. Several studies have indicated that progestins such as medroxyprogesterone or norethindrone are less well tolerated because they have several adverse effects, ${ }^{22,23}$ which can be explained by their affinities for the androgenic and glucocorticoid receptors. ${ }^{24}$

\section{Spotting}

In a large study in which several doses were evaluated, frequency of endometrial bleeding slightly increased after the first cycle of treatment and decreased during the subsequent cycles, being $8 \%$ at 12 months in the estradiol and $2 \mathrm{mg}$ drospirenone group. ${ }^{15}$

Also it has been observed that in drospirenone plus estradiol groups the mean bleeding days increased from 0 and 0.2 in the first treatment week to 1.6 to 2.2 at weeks 4 to 5 . The number of bleeding days varied from 0.2 to 1.7 through the entire treatment period, with no difference between treatment groups. ${ }^{16}$ This result agrees with that of another study in which a greater proportion of women in groups with estradiol plus drospirenone had bleeding in cycles 1 to 3 compared with those with estradiol monotherapy. ${ }^{17}$

It has also been reported that bleeding days decreased in the second half of the treatment. The maximum number of bleeding days was 1.8 at the sixth treatment week and decreased to 0.4 to 1.1 until the end of the study. ${ }^{18}$

\section{Breast pain}

Breast pain followed by headache were the main complaints reported by subjects in treated groups, while in the placebo group headache and abdominal pain were the main complaints: 11 cases of breast pain were reported in the $1 \mathrm{mg}$ drospirenone group, 3 in the $2 \mathrm{mg}$ drospirenone group, 2 in the $3 \mathrm{mg}$ drospirenone group, and 1 in the placebo group. Permanent bleeding was reported in a woman in group 2 which was treated by hysterectomy, which revealed adenomiosis and several leiomyomata. ${ }^{16}$ Adverse effects were breast pain (experienced by $1.7 \%$ ) and vaginal hemorrhage (1.6\%). Of those on estradiol monotherapy, $19.6 \%$ reported breast 
pain and $14.3 \%$ vaginal hemorrhage. ${ }^{17}$ In another study the most frequent adverse effect was breast pain followed by abdominal pain. ${ }^{18}$

\section{Weight}

Subjects receiving doses of 0.5 and $2 \mathrm{mg}$ drospirenone plus estradiol maintained or even lost weight $(0.4$ and $0.8 \mathrm{~kg}$ respectively) compared with baseline. ${ }^{15}$

Another study, which evaluated 225 healthy postmenopausal women, no changes were found in weight between the different drospirenone plus estradiol groups. ${ }^{16}$ However, in a large study a significant decrease in mean body weight from baseline was observed at cycle 13 in the groups with 2 and $3 \mathrm{mg}$ drospirenone. ${ }^{17}$

\section{Health-related quality of life}

Mean scores on sf-36 for physical and mental health have been evaluated and were similar among the groups. Women's health questionnaire showed an improvement in somatic symptoms by the end of cycle 13 in those groups receiving 2 and $3 \mathrm{mg}$ drospirenone in addition to estradiol compared with estradiol monotherapy. No differences in vasomotor symptoms were found between the groups. Psychological and somatic symptoms had a positive mean change but without statistical significance. ${ }^{17}$ In the patient's satisfaction questionnaire, all women in all treatment groups agreed that there were benefits with HT. ${ }^{17}$

\section{Conclusion}

Drospirenone $2 \mathrm{mg}$ in addition to estradiol $1 \mathrm{mg}$ is a good option for postmenopausal women, because of its proven efficacy, safety and tolerability, and because it does not have the adverse effects of other progestins, owing to its lack of androgenic, estrogenic or glucocorticoid effect.

\section{Disclosures}

The author has no conflicts of interest to disclose.

\section{References}

1. Carranza-Lira S. Actualidades en terapia hormonal. Universum-Mexico. 2008.

2. Carranza-Lira S, Cortés-Fuentes E. Modification of vasomotor symptoms after different treatment modalities in the postmenopause. Int $J$ Gynaecol Obstet. 2001;73(2):169-171.

3. Utian WH, Shoupe D, Bachmann G, Pinkerton JV, Pickar JH. Relief of vasomotor symptoms and vaginal atrophy with lower doses of conjugated equine estrogens and medroxyprogesterone acetate. Fertil Steril. 2001;756(6):1065-1079.
4. Rossouw JE, Anderson GL, Prentice RL, et al. Risk and benefits of estrogen plus progestin in healthy postmenopausal women. Principal results from the Women's Health Initiative randomized controlled trial. JAMA. 2002;288(3):321-333.

5. Harman SM. Estrogen replacement in menopausal women: Recent and current prospective studies, the WHI and the KEEPS. Gend Med. 2006;3(4):254-269.

6. Figueroa-Casas PR, Ettinger B, Delgado E, Javkin A, Vieder C. Reversal by medical treatment of endometrial hyperplasia caused by estrogen replacement therapy. Menopause. 2001;8(6):420-423.

7. Lobo RA. Absorption and metabolic effects of different types of estrogen and progestogens. Obstet Gynecol Clin North Am. 1987;14(1):143-167.

8. Jackson VP, San Martin JA, Secrest RJ, et al. Comparison of the effect of raloxifene and continuous combined hormone replacement therapy on mammographic breast density and breast tenderness in postmenopausal women. Am J Obstet Gynecol. 2003;188(2):389-394.

9. Genazzani AR, Mannella P, Simoncini T. Drospirenone and its antialdosterone properties. Climacteric. 2007;10 Suppl 1:11-18.

10. Sitruk-Ware R. Pharmacology of different progestogens: the special case of drospirenone. Climacteric. 2005;8 Suppl 3:4-12.

11. Ylikorkala O. Drospirenone, a progestin with a unique cardiovascular profile, for safe contraception and treatment of menopausal symptoms. Climacteric. 2005;8 Suppl 3:1-3.

12. Losert W, Casals-Stenzel J, Buse M. Progestogens with antimineralocorticoid activity. Arzeneimuttelforschung. 1985;35(2):459-471.

13. Oelkers W, Berger V, Bolik A, et al. Dihydrospirorenone, a new progestogen with antimineralocorticoid activity: effects on ovulation, electrolyte excretion, and the renin-aldosterone system in normal women. J Clin Endocrinol Metab. 1991;73(4):837-842.

14. Oelkers W. Drospirenone, a progestogen with antimineralocorticoid properties: a short review. Mol Cell Endocrinol. 2004;217(1-2):255-261.

15. Archer DF. Drospirenone and estradiol: a new option for the postmenopausal woman. Climacteric. 2007;10 Suppl 1:3-10.

16. Schürmann R, Holler T, Benda N. Estradiol and drospirenone for climacteric symptoms in postmenopausal women: a double-blind, randomized, placebo-controlled study of the safety and efficacy of three dose regimens. Climacteric. 2004;7(2):189-196.

17. Archer DF, Thorneycroft IH, Foegh M, et al. Long-term safety of drospirenone-estradiol for hormone therapy: a randomized, double-blind, multicenter trial. Menopause. 2005;16(6):716-727.

18. Lee BS, Kang BM, Yoon BK, Choi H, Park HM, Kim JG. Efficacy and tolerability of estradiol $1 \mathrm{mg}$ and drospirenone $2 \mathrm{mg}$ in postmenopausal Korean women: A double-blind, randomized, placebo-controlled, multicenter study. Maturitas. 2007;57(4):361-369.

19. White WB, Pitt B, Preston RA, Hanes V. Antihypertensive effects of drospirenone with 17 beta-estradiol, a novel hormone treatment in postmenopausal women with stage 1 hypertension. Circulation. 2005;112(13):1979-1984.

20. White WB, Hanes V, Chauhan V, Pitt B. Effects of a new hormone therapy, drospirenone and 17-beta-estradiol, in postmenopausal women with hypertension. Hypertension. 2006;48(2):243-253.

21. Mallareddy M, Hanes V, White WB. Drospirenone, a new progestogen, for postmenopausal women with hypertension. Drugs Aging. 2007;24(6):453-466.

22. Panay N, Studd J. Progestogen intolerance and compliance with hormone replacement therapy in menopausal women. Hum Reprod Update. 1977;3(2):159-171.

23. Sherwin BB, Gelfand MM. A prospective one-year study of estrogen and progestin in postmenopausal women: effects on clinical symptoms and lipoprotein lipids. Obstet Gynecol. 1989;73(5 pt 1):759-766.

24. Sitruk-Ware R. Pharmacological profile of progestins. Maturitas. 2004;47(4):277-283. 